\title{
Half time of the diastolic aortoventricular pressure difference by continuous wave Doppler ultrasound: a measure of the severity of aortic regurgitation?
}

\author{
STEIN O SAMSTAD, LARS HEGRENAES, TERJE SKJAERPE, LIV HATLE \\ From the Section of Cardiology, Department of Medicine, Regional Hospital, Trondheim, Norway
}

SUMMARY Thirty four patients with aortic regurgitation were studied by continuous wave Doppler ultrasound. In 30 of these the regurgitation was graded by cineangiography as mild, $\dot{\dot{\omega}}$ moderate, or severe and in four severe regurgitation was confirmed at operation. The half times $\mathscr{W}_{\infty}$ of the aortoventricular pressure differences obtained with Doppler compared well with those 음 obtained from pressure recordings at catheterisation. The relation between pressure half times and cineangiographic gradings of severity was not consistent. Similarly, a control group of $\rightarrow$ patients without aortic regurgitation showed a wide range of the invasively recorded pressure half times which overlapped with those in patients with aortic regurgitation. This suggests that $\overrightarrow{0}$ factors such as systemic vascular resistance, and aortic and left ventricular compliance can have $\iota^{\infty}$ an appreciable effect on the pressure half time. If these factors are not included the method will i be of limited value, except in patients with pressure half times of $<300 \mathrm{~ms}$, when regurgitation invariably is severe.

These results suggest that at present the method is of value only in recognising the patients with the most severe aortic regurgitation who need early operation.

Aortic regurgitation can be diagnosed with high sensitivity and specificity by pulsed and continuous wave Doppler ultrasound. ${ }^{12}$ Provided the angle between the ultrasound beam and the regurgitant jet is small, the maximal jet velocities can be recorded with continuous wave Doppler and the instantaneous pressure difference between the aorta and the left ventricle can be calculated. ${ }^{3}$ The decline of this gradient throughout diastole can then be measured non-invasively. ${ }^{4-6}$

The rate of decrease of the aortoventricular pressure difference during diastole obtained by pressure recording or non-invasively by continuous wave Doppler has been used as a measure of the severity of aortic regurgitation. ${ }^{6-8}$ The rate of decline in this pressure difference, however, also depends on aortic compliance, total systemic vascular resistance, and the left ventricular compliance. ${ }^{8}$ The rate of decrease of the pressure difference can be expressed

Requests for reprints to Dr Stein O Samstad, Section of Cardiology, Department of Medicine, Regional Hospital, N-7006 Trondheim, Norway.

Accepted for publication 30 August 1988 by its pressure half time-that is the time from the peak pressure difference to a $50 \%$ decrease in that value. $^{79}$

The aim of our study was to assess whether this pressure half time obtained from the maximal velocity of the aortic regurgitation recorded by continuous wave Doppler ultrasound was a usefu measure of the severity of the aortic regurgitation. For this we studied $(a)$ the agreement between the non-invasive and the invasive methods by comparing the half time of the pressure difference calculated from the maximal velocities of the aortic regurgitation with that obtained from the aortic and left ventricular pressure recordings at catheterisation; $(b)$ we compared the pressure half time of the aortic regurgitation with the angiographic assessment of severity; (c) we noted the range of the half times of the diastolic pressure difference between the aorta and left ventricle measured at catheterisation in patients without aortic regurgitation; and (d) we examined the relation between the pressure half time and the systemic vascular resistance in patients with aortic regurgitation.

The effect of aortic compliance upon the pressure 
Table 1 Data on patients with aortic regurgitation

\begin{tabular}{|c|c|c|c|c|c|c|c|c|}
\hline $\begin{array}{l}\text { Patient } \\
\text { No }\end{array}$ & $\begin{array}{l}\text { Age } \\
(y r)\end{array}$ & $\begin{array}{l}\text { Additional } \\
\text { diagnoses }\end{array}$ & $A G$ & $\begin{array}{l}H R \\
\text { (beats/min) }\end{array}$ & $\begin{array}{l}\underset{\text { (ms) }}{D P H T} \\
\text { (ms }\end{array}$ & $\begin{array}{l}I P H T \\
\text { (ms) }\end{array}$ & $\begin{array}{l}\text { SVR } \\
\left(\text { dyn.s. } \mathrm{cm}^{-5}\right)\end{array}$ & $\begin{array}{l}L V E D P \\
(\mathrm{~mm} H g)\end{array}$ \\
\hline $\begin{array}{r}1 \\
2 \\
3 \\
4 \\
5 \\
6 \\
7 \\
8 \\
9 \\
10 \\
11 \\
12 \\
13 \\
14 \\
15 \\
16 \\
17 \\
18 \\
19 \\
20 \\
21 \\
22 \\
23 \\
24 \\
25 \\
26 \\
27 \\
28 \\
29 \\
30 \\
31 \\
32 \\
33 \\
34\end{array}$ & 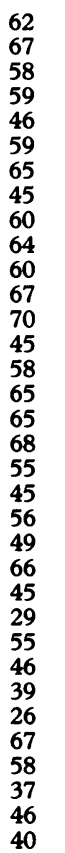 & $\begin{array}{l}\text { AS } \\
\text { MS, TR, TS } \\
\text { MR } \\
\text { MS } \\
\text { AS, MS, MR } \\
\text { AS, IHD } \\
\text { MS, MR } \\
\text { AS } \\
\text { AS, MS } \\
\text { MS } \\
\text { AS } \\
\text { AS } \\
\text { AS, MR, IHD } \\
\text { MR, IHD } \\
\text { MS } \\
\text { DCM } \\
\text { AS } \\
\text { AS } \\
\\
\text { AS }\end{array}$ & $\begin{array}{l}1+ \\
1+ \\
1+ \\
1+ \\
1+ \\
2+ \\
2+ \\
2+ \\
2+ \\
2+ \\
2+ \\
2+ \\
2+ \\
2+ \\
2+ \\
3+ \\
3+ \\
3+ \\
3+ \\
3+ \\
3+ \\
3+ \\
3+ \\
3+ \\
3+ \\
3+ \\
3+ \\
3+ \\
3+ \\
3+ \\
3+\star \\
3+\star \\
3+\star \\
3+\star\end{array}$ & $\begin{array}{r}52 \\
78 \\
68 \\
70 \\
74 \\
46 \\
72 \\
66 \\
66 \\
96 \\
78 \\
108 \\
67 \\
74 \\
71 \\
49 \\
50 \\
49 \\
70 \\
66 \\
58 \\
75 \\
59 \\
77 \\
67 \\
81 \\
47 \\
82 \\
90 \\
90 \\
80 \\
98 \\
66 \\
74\end{array}$ & $\begin{array}{l}702 \\
700 \\
623 \\
617 \\
500 \\
600 \\
533 \\
496 \\
460 \\
450 \\
440 \\
390 \\
360 \\
358 \\
353 \\
670 \\
623 \\
556 \\
453 \\
405 \\
380 \\
360 \\
352 \\
350 \\
320 \\
310 \\
255 \\
240 \\
215 \\
205 \\
245 \\
218 \\
170 \\
160\end{array}$ & $\begin{array}{l}550 \\
540 \\
760 \\
420 \\
460 \\
540 \\
430 \\
410 \\
390 \\
400 \\
470 \\
260 \\
312 \\
370 \\
340 \\
650 \\
560 \\
470 \\
440 \\
500 \\
380 \\
350 \\
390 \\
310 \\
240 \\
230 \\
300 \\
300 \\
160 \\
170\end{array}$ & $\begin{array}{r}1614 \\
1717 \\
1460 \\
2026 \\
3097 \\
1800 \\
1513 \\
1518 \\
3277 \\
793 \\
3370 \\
1496 \\
1776 \\
818 \\
3779 \\
3333 \\
1275 \\
1990 \\
1080 \\
1096 \\
1150 \\
2249 \\
2491 \\
753 \\
1383 \\
1194 \\
1112 \\
1909 \\
\end{array}$ & $\begin{array}{r}15 \\
14 \\
15 \\
10 \\
4 \\
20 \\
16 \\
12 \\
14 \\
16 \\
18 \\
20 \\
30 \\
10 \\
8 \\
36 \\
12 \\
14 \\
32 \\
10 \\
28 \\
10 \\
36 \\
28 \\
20 \\
24 \\
18 \\
28 \\
20 \\
22\end{array}$ \\
\hline
\end{tabular}

AG, cineangiographic grading $\left(1+=\right.$ mild, $2+=$ moderate, and $3+=$ severe aortic regurgitation; $3 t^{\star}$ severe aortic regurgitation at operation (patients 31-34 not included in the study group)); DPHT, Doppler aortoventricular pressure difference half time; IPHT, invasive aortoventricular pressure difference half time; SVR, systemic vascular resistance; HR, heart rate; LVEDP, left ventricular end diastolic pressure; IHD, ischaemic heart disease; MR, mitral regurgitation; AS, aortic stenosis; MS, mitral stenosis; TR, tricuspid regurgitation; TS, tricuspid stenosis; DCM, dilated cardiomyopathy; AE, acute endocarditis; PL, paravalvar leak.

half time could not be evaluated because there was no method of recording this variable.

\section{Patients and methods}

PATIENTS (Table 1)

We studied 30 patients with aortic regurgitation admitted to the hospital during a two year period. Left heart catheterisation was done in all and 28 also had right heart catheterisation. Only patients who showed a distinct envelope of the maximal velocities of the aortic regurgitation on the Doppler recording were included in the study. Fifty nine per cent of the patients with angiographic evidence of aortic regurgitation were included in the study.

Eighty nine per cent of the patients with severe, $50 \%$ with moderate, and only $20 \%$ with mild regurgitation at angiography were included. The Doppler recordings were made within three days of the invasive study, usually the day before catheterisation. All recordings were analysed blindly after the end of the study.
In addition to the study group four patients with severe aortic regurgitation verified at operation were studied with Doppler ultrasound. These patients did not have catheterisation before operation.

The control group consisted of 30 patients without aortic regurgitation who had left heart catheterisation, including an aortic root contrast injection, for ischaemic heart disease (table 2).

\section{DOPPLER ECHOCARDIOGRAPHY}

Continuous wave Doppler recordings were made on an Irex System IIIB ultrasonograph with both a combined two dimensional and $2 \mathrm{MHz}$ Doppler transducer and a non-imaging $2 \mathrm{MHz}$ Doppler transducer. The maximal velocity of the aortic regurgitation was recorded from apical, parasternal, and suprasternal positions, and the recording with the highest velocity and best defined maximal velocity envelope was used for measurements.

A line was drawn along the maximal velocity envelope. Another line, parallel to the baseline, was then drawn at the velocity corresponding to the 
Table 2 Comparison between patients without aortic regurgitation and those with aortic regurgitation

\begin{tabular}{|c|c|c|c|c|c|c|}
\hline & $\begin{array}{l}\mathrm{Age} \\
(y r)\end{array}$ & $\begin{array}{l}H R \\
\text { (beats/min) }\end{array}$ & $\underset{(m s)}{D P H T}$ & $\begin{array}{l}I P H T \\
(m s)\end{array}$ & $\begin{array}{l}\text { SVR } \\
(\text { dyn.s.cm }\end{array}$ & $\begin{array}{l}\text { LVEDP } \\
(m m \mathrm{Hg})\end{array}$ \\
\hline $\begin{array}{l}\text { Control group }(n=30)(\text { Mean }(S D)) \text { : } \\
\text { Minimum } \\
\text { Maximum }\end{array}$ & $\begin{array}{l}57(7) \\
37 \\
67\end{array}$ & $\begin{array}{l}59(10) \\
40 \\
78\end{array}$ & & $\begin{array}{l}613(157) \\
380 \\
910\end{array}$ & & $\begin{array}{l}14 \cdot 3(6 \cdot 8) \\
6 \\
30\end{array}$ \\
\hline $\begin{array}{l}\text { Aortic regurgitation (Mean (SD)): } \\
\text { Mild }(n=5) \\
\text { Moderate }(n=10) \\
\text { Severe }(n=15) \\
\text { Mild, moderate, and severe }(n=30) \\
\text { Severe at operation }(n=4)\end{array}$ & $\begin{array}{l}58(7) \\
59(8) \\
51(13) \\
55(11) \\
45(9)\end{array}$ & $\begin{array}{l}68(9) \\
74(17) \\
67(14) \\
69(14) \\
79(13)\end{array}$ & $\begin{array}{l}628(82) \\
444(82) \\
380(144) \\
445(144) \\
198(40)\end{array}$ & $\begin{array}{l}546(131) \\
392(79) \\
363(141) \\
403(136)\end{array}$ & $\begin{array}{l}1704(239) \\
1943(967) \\
1771(912) \\
1824(851)\end{array}$ & $\begin{array}{l}11.6(4 \cdot 7) \\
16.4(6.2) \\
22.5(8 \cdot 8) \\
18.7(8.4)\end{array}$ \\
\hline
\end{tabular}

DPHT, Doppler aortoventricular pressure difference half time; IPHT, invasive aortoventricular pressure difference half time; SVR, systemic vascular resistance; $H R$, heart rate; LVEDP, left ventricular end diastolic pressure.

maximal velocity divided by $1 \cdot 4$. The pressure half time can then be measured along the baseline, from the time of maximal velocity and maximal aortoventricular pressure difference, to the point at which the second line crosses the maximal velocity envelope (fig 1$)^{9}$

The decay in velocity is linear in patients with severe aortic regurgitation but it may be curvilinear in others. When diastole is too short for the two lines to cross before end diastole three different options for measurement of the pressure half time have to be considered (fig 2).

(a) A line drawn along the maximum velocity envelope can be prolonged beyond end diastole, but this is ambiguous in patients with a curvilinear $\vec{A}$ velocity decay. The use of this method in such patients gives variable results with varying heart rate $O$ and diastolic length. The result varies depending on $\frac{\circ}{5}$ whether only the initial steeper part of the curve is present or, as with the slower heart rate, a less steep $\frac{7}{0}$ part is included in the recording.

(b) A straight line drawn through the maximal $\overrightarrow{0}$ velocities in early and late diastole and with prolon- 0 gation beyond the velocity envelope crosses the horizontal line of half the initial pressure difference either during diastole or after. This option is also liable to variation in pressure half time with varying heart rates and diastolic length.
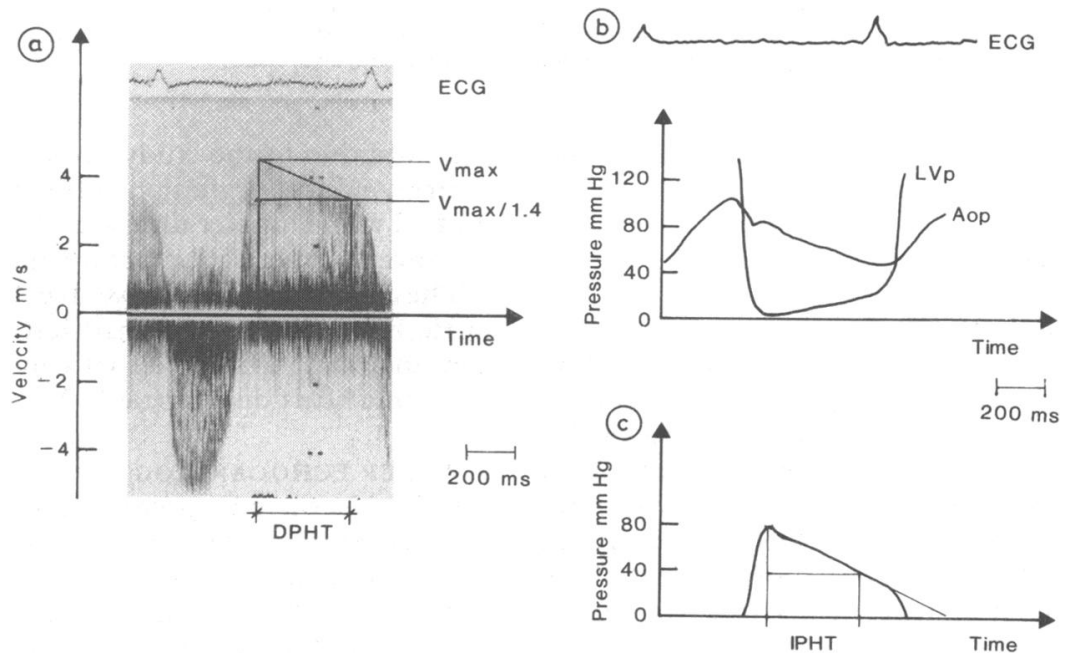

Fig 1 Continuous wave Doppler echocardiogram and pressure recordings from patient 21 with combined aortic stenosis and regurgitation. The regurgitation was graded as severe $(3+)$ at angiography. (a) Measurement of pressure half time from the Doppler recording $(D P H T)$. (b) left ventricular $(L V)$ and aortic ( $A o)$ pressures recorded during pull back of the catheter are superimposed for beats with equal $R R$ intervals. (c) Difference between the pressures during diastole and the invasively measured pressure half time (IPHT). The paper speed in the recordings was $50 \mathrm{~mm} / \mathrm{s}$. 

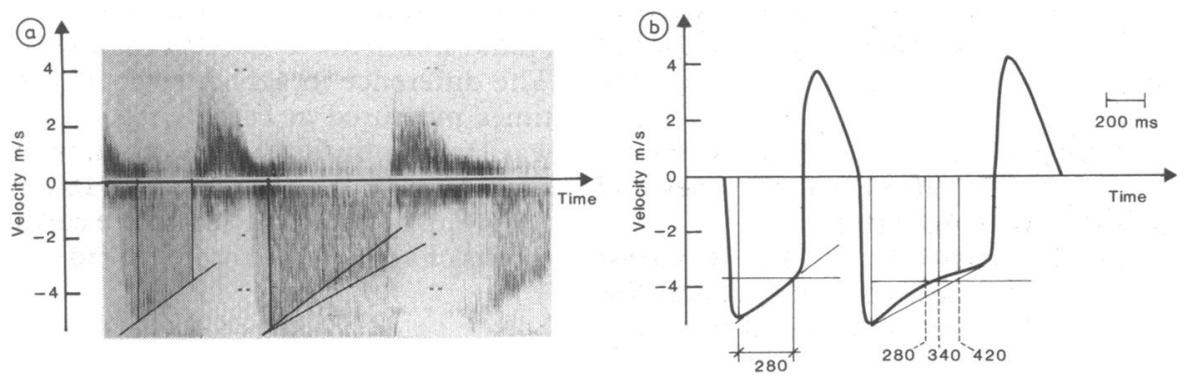

Fig 2 (a) Aortic stenosis and regurgitation recorded by continuous wave Doppler from the right sternal border. The regurgitation is away from the transducer and is seen below the zero line. (a) Tracing of the maximal velocity of the regurgitation shows three options for measurement of the half time of aortoventricular pressure difference. (1) $340-$ the crossing point between the maximal velocity envelope and the velocity where the peak pressure difference is halved (that is the peak velocity divided by 1.4). (2) 420 - the crossing point between a line drawn through the maximum and minimum diastolic velocities of the regurgitation jet and the velocity where the peak pressure difference is halved. (3) 280-the crossing point between a line along the initial slope of the maximal velocities and the velocity at which the aortoventricular pressure difference is halved.

When the decrease in velocity is linear, as in the first diastolic period in (a) where the RR interval is short, all the methods gave a similar pressure half time (280 ms) whereas for the next beat with longer diastole and a curvilinear maximal velocity envelope the three methods give different results, 340, 420, and $280 \mathrm{~ms}$ respectively.

(c) A straight line drawn along the initial slope of the recorded maximal velocities from the aortic regurgitation is less susceptible to variations in heart rate than the other two options. Usually the initial part of the velocity decrease is linear and easy to define. This method may, however, distinguish less well between curves with an initially rapid but then slower velocity decay and curves where the velocity decay is rapid throughout diastole, as seen in patients with severe aortic regurgitation. Thus none of these methods is ideal.

In this study we measured the pressure half time from the Doppler recording along the maximum velocity of the curve whenever possible (fig 1). In patients with a linear velocity decay the line along the maximum velocities was extended beyond end diastole when necessary. In patients with a curvilinear velocity decrease we used a line extended along the initial slope (fig 2). The time duration from the peak velocity to the crossing point of the line along the maximal velocities and the line indicating half the initial pressure difference was defined as the Doppler pressure half time (DPHT). This was calculated on the basis of recordings from 4-6 beats.

\section{CATHETERISATION}

At left and right heart catheterisation pressures were recorded with fluid filled catheters connected to Elema 746 pressure transducers. The pressure difference between the aorta and the left ventricle was obtained by superimposing pressures recorded during pull back of the catheter from the left ventricle to the ascending aorta. Beats with comparable RR intervals were used.

Left ventricular end diastolic pressures were recorded as recommended by the report of the World Health Organisation/International Society and Federation of Cardiology Task Force on haemodynamics. $^{10}$ The fourth intercostal space in the anterior axillary line was used as zero level for pressure measurements. ${ }^{11}$

We used a modification of the pressure half time of diastolic pressure in the ascending aorta as described by Libanoff. ${ }^{7}$ But unlike Libanoff, we included the left ventricular diastolic pressures in the calculation and used the same approach as for the non-invasive method (fig 1). A normal range of invasively measured pressure half times was obtained from the control group of cardiac patients without aortic regurgitation. Cardiac output was obtained by the Fick method and systemic vascular resistance was calculated in the 28 patients of the study group who had both left and right heart catheterisation ${ }^{12}$ (table 1).

\section{CINEANGIOGRAPHY}

Cineangiographic views were taken in the anterioposterior projection of a bolus injection of $50 \mathrm{ml}$ Isopaque (Nycomed, Oslo) at an injection rate of $18 \mathrm{ml} / \mathrm{s}$ into the ascending aorta. At examination of the cineangiographic films the regurgitations were graded according to $\mathrm{Eie}^{13}$ :

No aortic insufficiency $(0)-\mathrm{No}$ regurgitation through the aortic valves could be shown. 
Mild aortic insufficiency $(1+)$-Regurgitation of contrast medium could be seen midway down the left ventricular cavity and was then expelled in the following systole.

Moderate aortic insufficiency $(2+)$-Contrast could be seen down to the left ventricular apex and was expelled in the following systole.

Severe aortic insufficiency $(3+)$-Contrast medium was regurgitated down to the apex and was not expelled in the following systole, and there was opacification of an increased residual volume.

\section{STATISTICAL ANALYSIS}

Means (SD) were calculated for the data from the invasive and non-invasive recordings. The sample points from each patient were based on the average of the recordings from 4-6 heart beats. We tested the differences between the means of the samples in the subgroups (defined by angiographic grading) by the Bonferroni $t$ test as described by Glantz. ${ }^{14}$

The agreement of measurement of the pressure difference half times between the two methods was analysed according to the method recommended by Bland and Altman. ${ }^{15}$

\section{Results}

Tables 1 and 2 give the results for the study group and the control group. Cineangiography showed mild aortic regurgitation in five patients, moderate regurgitation in 10, and severe regurgitation in 15.
COMPARISON OF PRESSURE HALF TIME

MEASURED NON-INVASIVELY AND INVASIVELY

The difference in agreement between pressure half $\overrightarrow{\vec{F}}$ times measured at catheterisation and by Doppler was large both for the whole study group (limits of agreement from $-106 \mathrm{~ms}$ to $+184 \mathrm{~ms}$ ) and for the $\frac{\bar{\omega}}{\bar{N}}$ subgroup of patients with severe aortic regurgitation (limits of agreement from $95 \mathrm{~ms}$ to $+127 \mathrm{~ms}$ ) (fig 3).

\section{COMPARISON OF PRESSURE HALF TIME MEASURED NON-INVASIVELY AND}

ANGIOGRAPHIC GRADE

The pressure half times measured by Doppler were not significantly different in those with severe (mean pressure half time 385 (144) ms, range 205-670 ms) and moderate regurgitation (mean $444(82) \mathrm{ms}$, range 353-600 ms), $\mathrm{p}>0.05$ (fig 4).

The mean pressure half times for mild regurgitation (628 (82) ms, range 500-702 ms) were significantly different from those associated with severe ( $p<0.05$ ) but not moderate regurgitation ( $p>$ $0.05)$. There was, however, wide variation within each grade of angiographic severity and considerable overlap between the groups (fig 4).

The pressure half times measured at catheterisation in the control group (mean (SD) 613 (157) ms, range $380-910 \mathrm{~ms}$ ) were significantly different only from those of the patients with severe regurgitation $(\mathrm{p}<0.05)$.

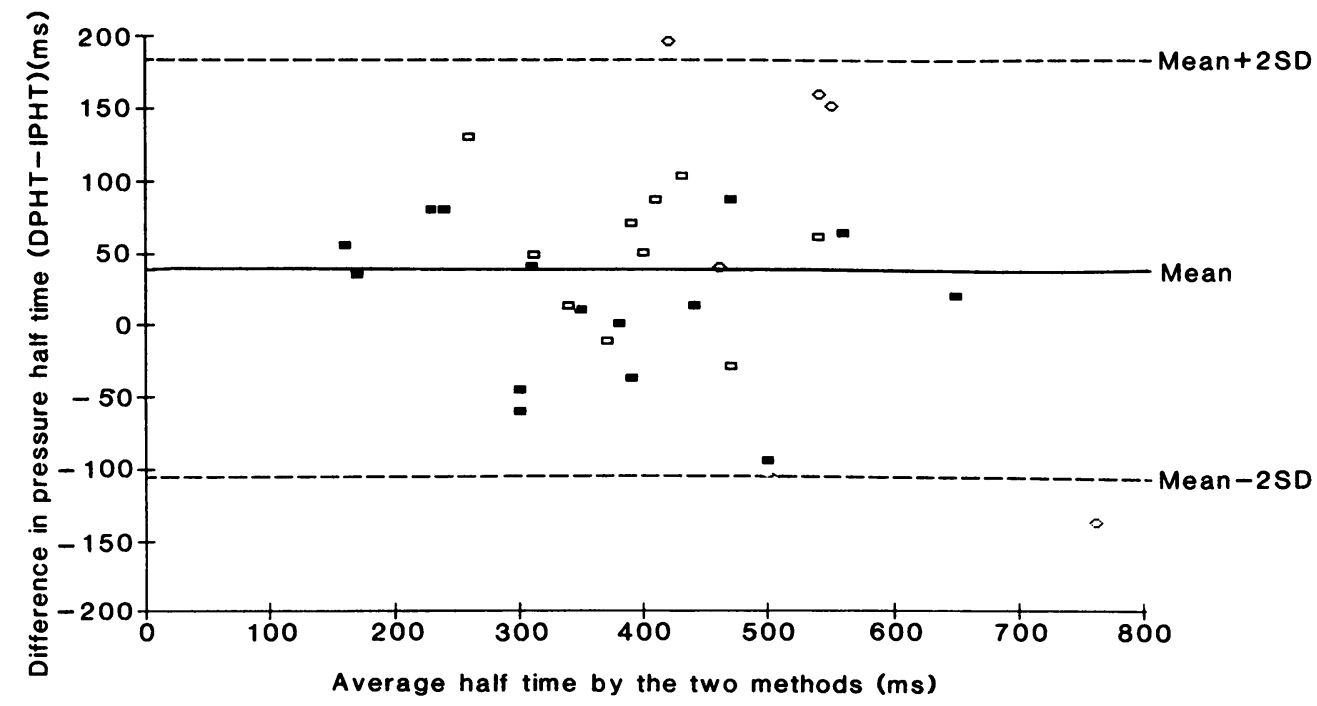

Fig 3 Relation of the differences in pressure half time measured by the Doppler technique (DPHT) and by catheterisation (IPHT) to the mean pressure half time by both techniques. At angiography 15 patients were graded as having severe ( $\square$ ), 10 moderate $(\square)$, and 5 mild $(\diamond)$ aortic regurgitation. 


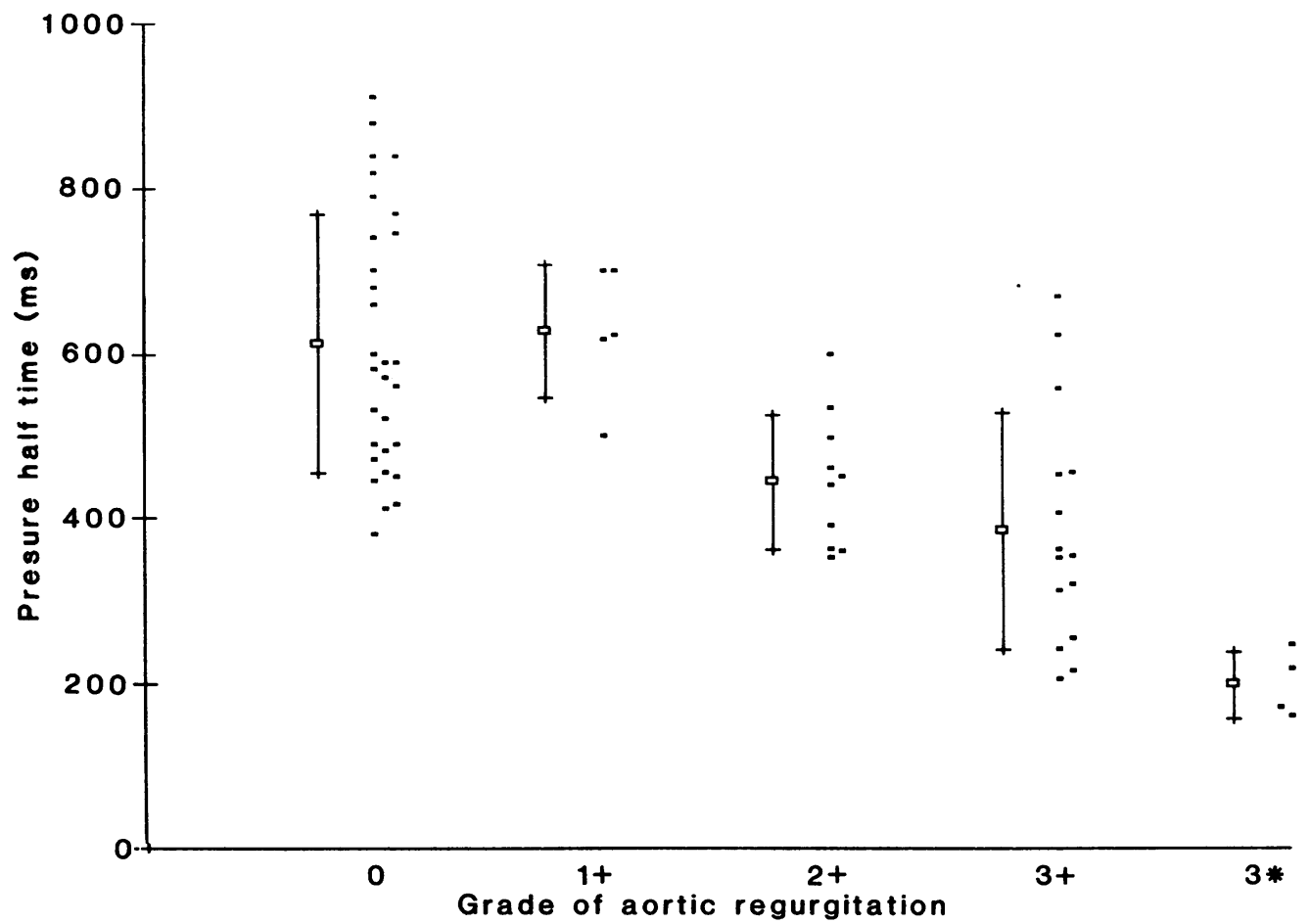

Fig 4 Comparison between the pressure half time and the severity of aortic regurgitation assessed by angiography. In the control group (0) the half time was obtained from invasive measurements and in patients with aortic regurgitation from the non-invasive measurements $(1+-3+)$. Angiographic assessment : $0=$ no aortic regurgitation, $1+=$ mild, $2+=$ moderate, and $3+=$ severe aortic regurgitation. Patients with severe aortic regurgitation at operation are shown as $3^{\star}$. Mean (2SD) half times for each group are shown.

PRESSURE HALF TIMES MEASURED NONINVASIVELY AND SYSTEMIC VASCULAR RESISTANCE

There was a positive correlation between pressure half times measured by Doppler and systemic vascular resistance in patients with severe regurgitation $(r=0.65, p=0.012$, SEE $116 \mathrm{~ms})$. There was no significant difference in systemic vascular resistance between the groups classified as having mild, moderate, or severe regurgitation at cineangiography.

The pressure half times as measured with Doppler did not correlate with heart rate, systolic or diastolic aortic pressure, or left ventricular end diastolic pressure. No significant difference in heart rate or systolic aortic pressure was found between the subgroups at catheterisation $(p>0.05)$. Left ventricular end diastolic pressure was significantly higher in the patients with severe aortic regurgitation (mean (SD) $22.5(8.8) \mathrm{mm} \mathrm{Hg}$ ) than the patients with mild regurgitation (mean 16.4 (6.2) $\mathrm{mm} \mathrm{Hg})(p<0.05)$.

The patients showing the largest overlap in pres- sure half time between the groups with moderate and severe aortic regurgitation (patients 15,16 , and 17) had either severe regurgitation with high systemic vascular resistance (patients 16 and 17) or moderate regurgitation with low systemic vascular resistance (patient 15).

The four patients with severe aortic regurgitation who went to surgery without catheterisation had pressure half times measured by Doppler (mean 198 (40.2) $\mathrm{ms}$, range 160-245 ms) that were significantly shorter than in the subgroups of patients with mild or moderate regurgitation at angiography $(p<0.05)$.

\section{Discussion}

The results indicate that the half time of the aortoventricular pressure difference can be assessed non-invasively from the maximal velocity of aortic regurgitation estimated by continuous wave Doppler ultrasound if signals have a well defined maximal velocity envelope.

A comparison of the pressure half times in those 
with various angiographic grades of severity showed that neither the difference between means of moderate and severe nor that between means of mild and moderate regurgitation were significant. Only the mean of mild regurgitation differed significantly from the mean of severe regurgitation. In the four patients with severe regurgitation who went to operation without catheterisation, however, the pressure half times were significantly shorter than in the patients with mild or moderate regurgitation. Only in patients with severe regurgitation were pressure half times shorter than $300 \mathrm{~ms}$ recorded at catheterisation.

There may be several reasons for the wide range of pressure half times within each group and the overlap between the groups. Angiographic grading is a much less accurate estimate of the degree of regurgitation than the regurgitation fraction. ${ }^{1617}$ On the other hand, the pressure decrease in the aorta during diastole is dependent on the volume loss both to the left ventricle and to the systemic arteries. Provided that compliance and early diastolic pressure in the aorta are constant, a decrease in systemic vascular resistance would result in a faster volume transport to the body, and hence a more rapid decrease in aortic pressure. This would result in both a smaller volume loss to the left ventricle because of the reduced pressure and at the same time a faster pressure drop and a shortened pressure half time. We found a positive correlation between systemic vascular resistance and pressure half time $(p=0.012)$ in patients in whom angiography showed severe regurgitation. However, because the patients included in this study were examined only once (without administration of drugs for provocation of changes in peripheral vascular resistance or for compliance measurements), the influence of systemic vascular resistance upon the pressure half time could not be evaluated further.

In patients with increased aortic compliance a larger volume variation may occur with less alteration in pressure, resulting in a longer pressure half time for the same volume change than in an aorta with normal or decreased compliance. With increased aortic compliance the pressure half time is influenced mainly by the left ventricular diastolic compliance.

For reliable measurements of the pressure half time of aortic regurgitation by continuous wave Doppler ultrasound a distinct envelope of the highest velocities from the regurgitation jet has to be obtained throughout diastole. The most common limitation in this study was insufficient delineation of the high velocities of the regurgitation jet. Because narrow jets give weaker signals than wide jets, patients with mild aortic regurgitation were less likely to be included in the study than patients with severe and moderate regurgitation.

The transducer needs to be positioned across the beginning of the jet to obtain a good envelope throughout diastole and a narrow angle between the regurgitation jet and the ultrasound beam gives a을 stronger signal than a wide angle. To obtain satisfac $-\frac{\tilde{D}}{\bar{D}}$ tory recordings in some patients the transducero position was changed from the apical position to the parasternal or suprasternal positions. When the origin and direction of the regurgitation jet can be visualised by colour coded Doppler, later experience $\vec{\omega}$ has indicated that a well defined envelope of the $\frac{\text { }}{5}$ maximal jet velocities can be more rapidly obtained, and with a higher success rate also in patients with? mild regurgitation.

The pressure half time is independent of the anglee् and not influenced by the blood pressure value,, whereas the deceleration rate depends both on the initial pressure and the rate of pressure decrease. $\vec{D}$ Others have measured the velocity half time or theo deceleration of aortic regurgitations. ${ }^{1819}$ These measurements differ from the pressure half time by being influenced both by the angle between the $e^{\circ}$ ultrasound beam and jet velocity and by changes in blood pressure in early diastole.

The choice of different options for measuring the pressure half time described in the methods is moreo important in patients with less severe regurgitation where the velocity decay is curvilinear unless diastole $\overrightarrow{\vec{\sigma}}$ is short. When the pressure half time was not reached 3 before end diastole the linear decay in the first part of $\supset$ diastole was used because this measurement was? independent of heart rate. This would, however, lead to relatively shorter half times in some of the patients® with mild and moderate regurgitation and may partly? account for the lack of a significant difference bet ween moderate and severe regurgitation. However, values $<350 \mathrm{~ms}$ were not seen in patients with milds or moderate regurgitation.

In patients with severe regurgitation there was no? difficulty with this measurement because they allo showed a linear velocity decay, with a continued rapid decrease in velocity throughout diastole. Thuso in addition to a shorter pressure half time in some of these patients, a continued rapid decrease in velocityN instead of a curvilinear decay was a useful indicator of the severity. A rapid heart rate would make this difference in the velocity curves in late diastole less obvious.

\section{Conclusions}

In patients with aortic regurgitation the half time of the aortoventricular pressure difference can be measured non-invasively with Doppler ultrasound. 
The wide scatter of pressure half times in the patients with mild or moderate regurgitation at cineangiography as well as in the control group suggests that other factors such as systemic vascular resistance and aortic and left ventricular compliance influence the pressure half time sufficiently to limit the usefulness of this measurement unless there is information on all variables. The method, however, is of value in detecting those patients with the most severe aortic regurgitation because the severity of the lesion and the need for early surgical intervention are not always recognised by clinical examination of these patients.

This study was supported by grants from the the Norwegian Council on Cardiovascular Diseases.

\section{References}

1 Quinones MA, Young JB, Waggoner AD, Ostojic MC, Ribeiro LGT, Miller RR. Assessment of pulsed Doppler echocardiography in detection and quantification of aortic and mitral regurgitation. Br Heart $J$ 1980;44:612-20.

2 Wautrecht JC, Vandenbossche JL, Englert M. Sensitivity and specificity of pulsed Doppler echocardiography in detection of aortic and mitral regurgitation. Eur Heart J 1984;5:404-11.

3 Hatle L, Angelsen B. Calculation of pressure drop. In: Doppler ultrasound in cardiology. 2nd ed. Philadelphia: Lea and Febiger, 1985:101-8.

4 Hatle L, Angelsen B. Aortic regurgitation. In: Doppler ultrasound in cardiology. 2nd ed. Philadelphia: Lea and Febiger, 1985:154-62.

5 Masuyama T, Kodama K, Kitabatake A, et al. Noninvasive evaluation of aortic regurgitation by continuous-wave Doppler echocardiography. Circulation 1986;73:460-6.

6 Teague SM, Heinsimer JA, Anderson JL, et al. Quantification of aortic regurgitation utilizing continuous wave Doppler ultrasound. J Am Coll Cardiol 1986;8:592-9.

7 Libanoff AJ. A hemodynamic measure of aortic regurgitation. Half-time of the rate of fall in aortic pressure during diastole. Cardiology 1973;58:162-73.

8 Judge TP, Kennedy JW. Estimation of aortic regurgitation by diastolic pulse wave analysis. Circulation 1970;41:659-65.

9 Hatle L, Angelsen B, Tromsdal A. Noninvasive assessment of atrioventricular pressure half-time by Doppler ultrasound. Circulation 1979;60:1096-104.

10 Bertrand ME, Widimsky J. Pressures. Eur Heart J 1985;6(suppl C):5-9.

11 Rokseth R, Helle I, Marstrander F, Storstein O. Reference level in pressure recordings during right heart catheterization. Scand J Clin Lab Invest 1960; 12:116-20.

12 Yang SS, Bentivoglio LG, Maranhao V, Goldberg $\mathbf{H}$. From cardiac catheterization data to hemodynamic parameters. 2nd ed. Philadelphia: FA Davies, 1978:56-62.

13 Eie H. Cineangiocardiography in cardiac valvular disease. Tidsskr Nor Laegeforen 1971;91:647-53.

14 Glantz SA. Primer of biostatistics. 2nd ed. New York: McGraw-Hill, 1987:64-100.

15 Bland JM, Altman DG. Statistical methods for assessing agreement between two methods of clinical measurement. Lancet 1986;i:307-10.

16 Hunt D, Baxley WA, Kennedy JW, Judge TP, Williams JE, Dodge HT. Quantitative evaluation of cineaortography in the assessment of aortic regurgitation. Am J Cardiol 1973;31:696-700.

17 Croft CH, Lipscomb K, Mathis K, et al. Limitations of qualitative angiographic grading in aortic or mitral regurgitation. Am J Cardiol 1984;53:1593-8.

18 Labotvitz AJ, Ferrara RP, Kern MJ, Bryg RJ, Mrosek DG, Williams GA. Quantitative evaluation of aortic insufficiency by continuous wave Doppler echocardiography. J Am Coll Cardiol 1986;8:1341-7.

19 Beyer RW, Ramirez M, Josephson MA, Shah PM. Correlation of continuous-wave Doppler assessment of chronic aortic regurgitation with hemodynamics and angiography. Am J Cardiol 1987;60:852-6. 